\title{
Shoot Regeneration in Root Cultures of Centaurium scilloides
}

\author{
Kazutaka NISHIKAWA*, Koichiro SHIMOMURA**, Toshiaki KAYANO*** \\ and Kanji ISHIMARU* \\ * Department of Applied Biological Sciences, Faculty of Agriculture, Saga University, \\ 1 Honjo, Saga 840, Japan \\ ** Tsukuba Medicinal Plant Research Station, National Institute of Health Sciences, \\ 1 Hachimandai, Tsukuba, Ibaraki 305, Japan \\ *** Department of Cell Biology, National Institute of Agrobiological Resources, \\ 1-2, 2-Chome Kannondai, Tsukuba, Ibaraki 305, Japan
}

Received 17 December 1996; accepted 4 March 1997

Centaurium group (Gentianaceae), consisting of about 30 species, ranges mainly in subtropical and temperate regions of the world. In Japan, only one native variety, C. japonicum Druce, grows in some islands (Yakushima island, etc.) in the southern most part of the country. A few tissue culture experiments on this genus have been done on $C$. rigualii [1] and C. erythraea $[2,3]$. C. scilloides, called "Komachirindou" in Japanese, is an small annual herb which is popularly used as a border in rock gardens and grown in pots and on verandas. In spite of being wellknown and used worldwide for its horticultural advantages, experiments on the breeding, mass propagation in vitro, transformation, and/or some tissue cultures have not been done. In this study, some tissue cultures (shoot and adventitious root) of this plant were established and the successful direct shoot regeneration from the root tissues was performed.

Seeds of C. scilloides, purchased from a market, were sterilized by the usual method $(2 \% \mathrm{NaOCl}, 9$

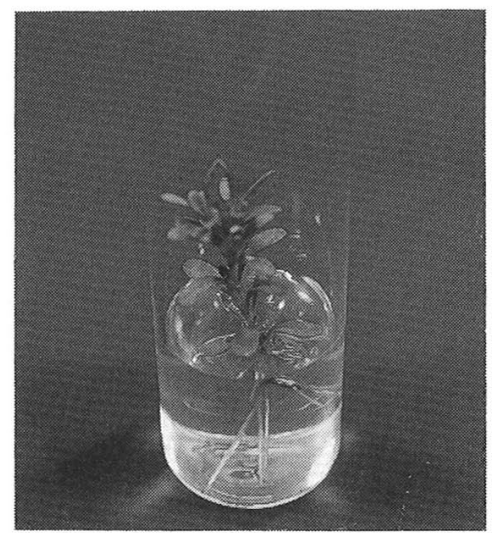

Fig. 1 Centaurium scilloides shoots cultured on hormone-free $1 / 2 \mathrm{MS}$ solid medium in the light. min.) and germinated aseptically on hormone-free half strength Murashige-Skoog (1/2 MS) [4] solid medium (solidified with $2.5 \mathrm{~g} / l$ gelrite, containing 30 $\mathrm{g} / \mathrm{l}$ sucrose) under light (16 hr photoperiod per a day, $3,000 \mathrm{~lx}$ ) condition at $25^{\circ} \mathrm{C}$. The axenic seedlings were transferred to same medium and subcultured under the above condition at one month intervals (Fig. 1).

After a year's subculture, the roots of the plantlets in vitro were cut ( $c a .3 \mathrm{~cm}$ of length) and transferred to hormone-free $1 / 2 \mathrm{MS}$ or Woody Plant (WP) [5] solid medium and cultured under the same conditions. After about 2 weeks of culture, several adventitious shoots were differentiated directly from the root tissues (ca. 10 shoots / root) on both (1/2 MS and WP) hormone-free media (Fig. 2).

The roots cut from the axenic plantlets in vitro were also inoculated into WP liquid medium supplemented with $3 \mathrm{mg} / l \mathrm{IAA}$ ( $50 \mathrm{~m} l$ medium in $100 \mathrm{~m} l$ flask) and cultured on a rotary shaker (100 rpm) in the light or dark. In both cultures, the adventitious shoots also regenerated directly from the roots in a fairly short time, i.e. about 3 weeks in the light and 6 weeks in the dark (Fig. 3). The shoots regenerated in

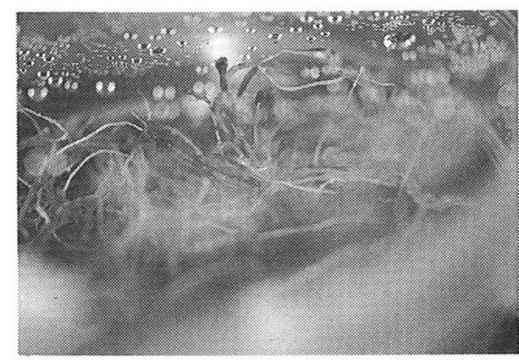

Fig. 2 Adventitious shoot regeneration from Centaurium scilloides roots cultured on hormone-free $1 / 2$ MS solid medium in the light. 
the dark did not contain chlorophylls at detectable levels when analysed using HPLC [6]. After the shoots in the dark condition were cut, transferred and cultured under illumination, they accumulated chlorophylls. The regenerants obtained in either solid or liquid media were not greatly different morphologically from in vitro plantlets from seedlings.

After acclimatization by dipping the root portion into water (in a beaker) for 4 days in a laboratory room, the plantlets regenerated directly from the root

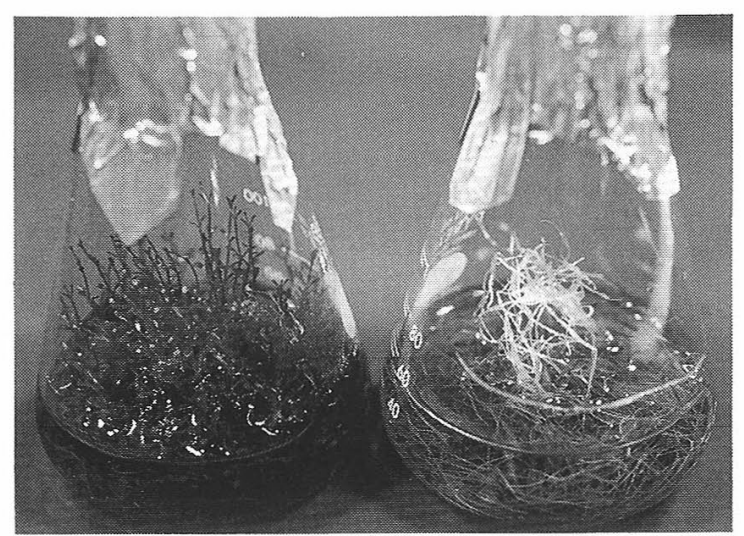

Fig. 3 Adventitious shoot regeneration from Centaurium scilloides roots cultured in WP liquid medium with $3 \mathrm{mg} / l$ IAA in the light (left) or dark (right).

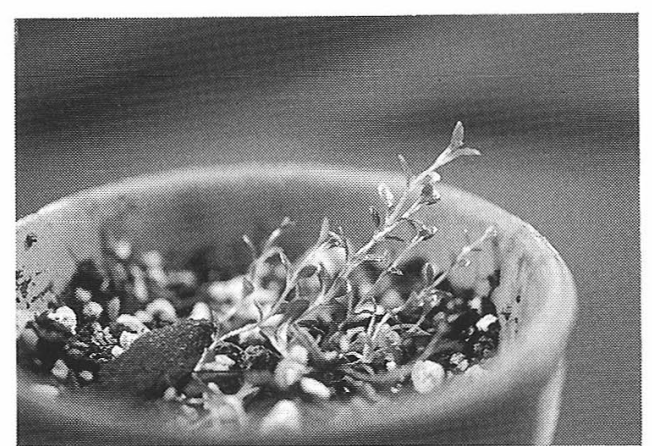

Fig. 4 Two-month-old plantlets of Centaurium scilloides after transplant to a pot. tissues in either solid or liquid media were successfully transplanted to soil (Fig. 4).

The experiments mentioned above firstly demonstrated the establishment of some tissue cultures (shoot and adventitious root) of C. scilloides which would be the useful materials for further studies (biochemistry, genetic transformation, preservation, production of secondary metabolites, etc.) of this plant. The successful direct shoot regeneration from the root tissues under the above culture conditions also indicated a good system for masspropagation of this plant in vitro and the possibility of getting transgenic plants by Agrobacterium rhizogenes-mediated genetic transformation.

\section{Acknowledgements}

This work was supported in part by the subsidy from The San-Ei-Gen Foundation for Food Chemical Research and by a special coordination fund for promoting science and technology in the basic research core system by the Science and Technology Agency.

\section{References}

[1] Gonzalez-Benito, M.E., Perez, C., 1994. Botanic Gardens Micropropagation News, 1: 82-84.

[2] Meravy, L., 1987. Biologia Plantarum, 29: 247252.

[ 3 ] Benes, K., 1985. Acta Universitatis Agriculturae Brno, A., 33: 417-421.

[4] Murashige, T., Skoog, F., 1962. Physiol. Plant., 15: $473-497$.

[5] Lloyd, G.B., McCown, B.H., 1980. Int. Plant. Prop. Soc., 30: 421-427.

[6] Ishimaru, K., Arakawa, H., Yamanaka, M., Shimomura, K., 1994. Phytochemistry, 35: 365369. 